\title{
Hypolipidemic Effect of the Autoclaved Extract Prepared from Pea (Pisum sativum L.) Pods In Vivo and In Vitro
}

\author{
Kae INAGAKI ${ }^{1,2}$, Yuuki NishimURA ${ }^{1}$, Emiko IWATA ${ }^{3}$, Sachinobu MANABE ${ }^{2}$, \\ Masahiro GoTo ${ }^{1}$, Yoshio OGURA ${ }^{1}$ and Hisako HoтTA ${ }^{1}$ \\ ${ }^{1}$ Faculty of Home Economics, Kobe Women's University, 2-1 Aoyama, \\ Higashisuma, Suma-ku, Kobe 654-8585, Japan \\ ${ }^{2}$ Faculty of Health Science, Hyogo University, 2311 Shinzaike, Hiraokacho, Kakogawa 675-0195, Japan \\ ${ }^{3}$ Department of Food and Nutrition, Kanazawa Gakuin Junior College, \\ 10 Suemachi, Kanazawa 920-1392, Japan
}

(Received March 4, 2016)

\begin{abstract}
Summary By autoclaving, we obtained a polyphenol and dietary fiber from pea (Pisum sativum L.) pods in parallel without acid or alkali treatment or organic solvent extraction. Rats fed a high-sucrose (HS) diet containing 3\% autoclaved extract (AE) for 4 wk exhibited significantly lower serum triglyceride and total cholesterol levels than rats fed a HS diet. $\mathrm{AE}$ and soluble dietary fiber (SDF) from AE exhibited pancreatic lipase inhibitory activity at $13.3 \mathrm{mg} / \mathrm{mL}$ in vitro. $\mathrm{AE}$ and insoluble dietary fiber (IDF) from AE adsorbed cholesterol. In total, $30 \%$ and $10 \%$ of a cholesterol micelle were significantly adsorbed by $2,000 \mathrm{mg}$ of $\mathrm{AE}$ and $100 \mathrm{mg}$ of IDF from $\mathrm{AE}$ in $7 \mathrm{~mL}$, respectively. The amount of bifidobacteria in the cecum of the AE group was significantly increased compared with that in the HS group. These results suggest that AE has hypolipidemic, bifidogenic potential.
\end{abstract}

Key Words pea pod, dietary fiber, polyphenol, lipase activity, bifidobacteria

Peas are widely consumed and grown around the world. They represent a good source of protein, polysaccharides (dietary fiber, starch), and micronutrients (vitamins and trace minerals). In addition, they contain bioactive components, such as phenolic compounds. The shipment of peas in Japan was 12,700 tons in 2015 (http://www.e-stat.go.jp/SG1/estat/List. do?lid $=000001141603$ ). As the pea pod occupies 55\% of the total volume of peas, 6,985 tons of pods are produced annually, the majority of which are discarded as waste. The role of the pod in seed development has been studied in detail (1). Pea and broad bean pods are also sources of fiber-rich ingredients (2).

Dietary fiber is categorized as soluble dietary fiber (SDF) or insoluble dietary fiber (IDF). In particular, SDF has stimulatory effects on fecal lipid excretion, including fecal triglyceride and cholesterol $(3,4)$. Fecal lipid excretion was stimulated in the intestine by soluble fibers, such as guar gum or pectin, and soluble fibers also induced 3-hydroxy-3-methylglutaryl coenzyme A (HMG-CoA) reductase and cholesterol 7alpha-hydroxylase (CYP7A) (5, 6). IDF adsorbs moisture from food residue and increases the amount of feces (7). In addition, a lipid-lowering effect of the polyphenol present in IDF has been reported (8).

At present, there are no reports regarding the reuse of pea pods. An analytical study of broad beans and pea pods was previously published (2). The pea pod contains a neutral and acidic non-cellulosic polysaccharide, namely hemicellulose. In addition, it contains xylose

E-mail: inagaki@hyogo-dai.ac.jp and glucose due to the presence of xylan and xyloglucan. In our study, xylose and glucose were also detected in pea pods.

In our previous report, total dietary fiber prepared from pea pods displayed prebiotic activity in vitro (9). It was reported that xylo-oligosaccharide enhanced the growth of bifidobacteria and Bifidobacterium lactis in a simulated colon model (10). In this report, we determined the prebiotic activity of AE by FISH analysis.

As hemicellulose produces short-chain fatty acids, such as propionate and acetate, these acids were suggested to inhibit cholesterol biosynthesis (11). The presence of phenolic components in the seed coat and cotyledon of the pea was previously established (1), but the polyphenol composition of pea pods has not been analyzed. However, some related reports have been published. Insoluble carob fiber rich in polyphenols lowered total and LDL cholesterol levels in hypercholesterolemic subjects (8). The skin of peanuts and its fraction, which contains polyphenol, decreased serum lipid and cholesterol levels by inhibiting cholesterol absorption in the intestine (12).

In this study, our purpose was to clarify the effect of an autoclaved extract (AE) of pea pods on triglyceride and cholesterol levels in the serum, liver, and feces. We also investigated the effect of $\mathrm{AE}$ on lipase inhibitory activity and cholesterol adsorption in vitro. We selected AE to obtain bound-type polyphenols and total dietary fiber in parallel without acid or alkali treatment and organic solvent extraction. Most naturally occurring phenolic compounds are present as conjugates with polysaccharides and protein, as discovered by Klepacka et al. (13). 
In addition, Duenas et al. reported that releasing some phenolics via hydrolysis with various enzymatic preparations may result in 100-fold differences in their concentrations (1). On the other hand, constant recovery could be achieved via autoclaved extraction. We also expected to increase the functionality of $\mathrm{AE}$ by autoclaving.

\section{MATERIALS AND METHODS}

Preparation and characterization of AE. Peas (Pisum sativum L.), which were harvested in Wakayama Prefecture, Japan, were purchased from Japan Agricultural Cooperatives in Wakayama (JA Wakayama), and the pea pods were manually separated. Prepared pea pods were freeze-dried and milled to produce a powder that was finer than $0.5 \mathrm{~mm}$. AE was prepared using the following steps: $100 \mathrm{~g}$ of the powder of pea pods was added to $2 \mathrm{~L}$ of distilled water and extracted at $120^{\circ} \mathrm{C}$ for $30 \mathrm{~min}$ in an autoclave. This extract was filtered with a filter paper (Advantec No. 1, Japan), and the filtrate was freezedried and milled to produce a powder that was finer than $0.5 \mathrm{~mm}$. The powdered AE was used.

We analyzed the composition of lyophilized pea pods and AE. Carbohydrate levels were measured using the 3,5-dinitrosalicylic acid (DNS) method (14). Protein was measured via Lowry's method (15). Total lipid content was assessed using Folch's method (16). Vitamin C levels were measured via the hydrazine method (17). Polyphenol content was measured using the Folin-Ciocalteu method (18). The standard material was gallic acid. Sitosterol content was determined using a commercially available kit (Cholesterol E-Test, Wako Pure Chemical Industries, Ltd., Osaka, Japan). In this kit, including cholesterol oxidase, the substrate specificity against $\beta$-sitosterol was 95\% (Wako Technical Support). In addition, soluble dietary fiber (SDF) and insoluble dietary fiber (IDF) were measured using Prosky's method (19). Statistical analysis was performed by a $t$-test. Differences were considered significant when $p<0.05$.

Animal experiments. All animals and experimental protocols were approved by the ethical committee of Kobe Women's University on Animal Research (Permission No. 337, A32). Fifteen male Sprague-Dawley rats (4-wk-old) were purchased from CLEA Japan, Inc. (Shizuoka, Japan). They were divided into three groups, each containing five rats. All rats were housed in individual stainless steel cages in an air-conditioned room maintained at $23 \pm 1{ }^{\circ} \mathrm{C}$ with $50 \pm 5 \%$ humidity on a 12-h/12-h light-dark cycle. Rats were allowed free access to food and water. After a 3-d adaptation period with CE-2 (CLEA Japan, Inc., Tokyo, Japan), the animals were divided into three groups on the basis of body weight to ensure that the weight distribution among the groups was similar. The first group of rats comprised the control group, which was fed 10\% sucrose followed by AIN-93G, and contained (\% by weight) casein, 20\%; cornstarch, 52.9486\%; corn oil, 7\%; sucrose, 10\%; cellulose, 5\%; mineral mixture (AIN 93G), 3.5\%; vitamin mixture (AIN93), 1\%; and L-cysteine, 0.3\% (20). Soybean oil was replaced with corn oil to eliminate the cholesterol-lowering effect of linoleic acid in soybean oil.
The second group of rats comprised the high-sucrose (HS) group in which the sucrose content was changed to $25 \%$ instead of $10 \%$ sucrose. This added sucrose was replaced with cornstarch because HS diet feeding increased triglyceride and cholesterol levels in serum (21). The third group of rats was given a $25 \%$ sucrose diet containing 3\% AE. Cornstarch was replaced with $\mathrm{AE}$ because the highest component of $\mathrm{AE}$ was the reducing sugar whose content was more than half of AE. The energy value of each feed was as follows: the control and HS group corresponded to $400 \mathrm{kcal} / 100 \mathrm{~g}$; the AE group corresponded to $395.1 \mathrm{kcal}$.

Rats were fed the aforementioned diets for 4 wk. Body weight and food intake were measured three times a week. Fecal samples were collected during the last $4 \mathrm{~d}$ of the experimental period. On day 29, all rats were sacrificed. Before sacrifice, the animals were starved for $18 \mathrm{~h}$. The rats were anesthetized with an intraperitoneal injection of sodium pentobarbital at $66 \mathrm{mg} / \mathrm{kg}$ body weight; the abdomen was opened to collect a blood sample from a large abdominal vein. Blood samples were centrifuged at 3,500 rpm for $15 \mathrm{~min}$, and the obtained serum samples were used to measure glucose, cholesterol, and triglyceride levels. After the blood was drained for euthanasia, the liver and cecum were removed. The liver was homogenized in saline and stored at $-20^{\circ} \mathrm{C}$. The total weight of the removed cecum was measured. Afterward, the $\mathrm{pH}$ of the cecum was directly measured. All cecal content was scraped out and weighed. These samples were stored at $-20^{\circ} \mathrm{C}$ until analysis.

Analytical procedure for the serum and liver. The serum glucose level was determined via the glucose oxidase method using a commercially available kit (Glucose C II-Test, Wako). Total lipids in the liver were extracted according to the Folch method (16). Lipid extracts were dried and dissolved in $t$-butanol : methanol:Triton $\mathrm{X}-100(50: 25: 25, \mathrm{v} / \mathrm{v})$. The serum and liver cholesterol and triglyceride levels were determined using commercially available kits (Cholesterol E-Test and Triglyceride E-Test, respectively, Wako).

Analytical procedure for fecal lipids and bile acids. After determining the wet weight of feces, fecal samples were dried at $105^{\circ} \mathrm{C}$ for $17 \mathrm{~h}$. The feces were milled. Total lipids were extracted from $0.3 \mathrm{~g}$ of the dried feces followed by the Folch method (16). Ethanol extractions were conducted on the dried feces to measure bile acids. Collected ethanol extracts were washed with a mixture of distilled water and ethanol $(2: 8, \mathrm{v} / \mathrm{v})$ and dried with nitrogen gas. After the addition of $2 \mathrm{~mL}$ each of distilled water, ethanol, diethyl ether, and heptane with shaking, the ether layer was removed and dried with nitrogen gas. To perform deconjugation, $1.5 \mathrm{~mL}$ of $2 \mathrm{~N}$ sodium hydroxide and $0.5 \mathrm{~mL}$ of distilled water were added to the dried ether layer, and autoclaving was performed at $123^{\circ} \mathrm{C}$ for $240 \mathrm{~min}$. Then, $4 \mathrm{~mL}$ each of petroleum ether and hexane were added and mixed. The extracted ether layers were acidified with $2 \mathrm{~N}$ hydrochloric acid and extracted twice with diethyl ether. After washing the diethyl ether layers with distilled water, centrifuged supernatants were dried with nitrogen gas. Dried samples were dis- 
solved in methanol, and one part of the sample was used for the total bile acid measurement. The total bile acid content of the feces was determined using a Total Bile Acids Test (Wako). Methanol extracts were derivatized with diazomethane and dehydrated. They were dried again after being transferred to V vials. Dimethylethylsilyl ether (DMES) derivatization was performed overnight with $70 \mu \mathrm{L}$ of DMES (Tokyo Chemical Industry Co., Ltd., Tokyo, Japan). Samples containing DMES were washed with distilled water. The samples were finally centrifuged to completely remove DMES. Total bile acids were dissolved in $1 \mathrm{~mL}$ of hexane to obtain a sample for fecal bile acid analysis.

Using 7,12-dihydroxy-5 $\beta$-cholanoic acid as the internal standard, samples were injected into a gas chromatograph (Shimadzu GC-14A, Kyoto, Japan) with a flame ionization detector $(22,23)$. The column used was Rtx2000, which had an inner diameter, length, and film thickness of $0.25 \mathrm{~mm}, 30 \mathrm{~m}$, and $0.25 \mu \mathrm{m}$, respectively (Uniflex Co., Ltd., Schaumburg, IL). The measurement conditions were as follows: atten $=1$, splitless, column temperature of $218^{\circ} \mathrm{C}$, inlet temperature of $305^{\circ} \mathrm{C}$, and detector temperature of $300^{\circ} \mathrm{C}$. The determination of each bile acid concentration and identification of each component was performed using a Shimadzu Chromatopac C-R4A.

Measurement of pancreatic lipase activity in vitro. Lipase activity was determined via the rate of oleic acid released from triolein (24). Inhibition of lipase activity was estimated via the reduction of activity induced by AE. The substrate emulsion was prepared by sonicating triolein $(160 \mathrm{mg})$ with $3 \mathrm{~mL}$ of sodium taurocholate (TCA-Na $0.83 \mathrm{~mL} / \mathrm{mL}$ ) in $0.01 \mathrm{M}$ Tris- $\mathrm{HCl}$ buffer ( $\mathrm{pH} 7.4$ ) for $60 \mathrm{~min}$, and the resulting emulsion was diluted with $3 \mathrm{~mL}$ of TCA-Na containing AE or SDF from AE, polyphenol removed AE $(0,40,80 \mathrm{mg})$. After sonication for $60 \mathrm{~min}$, the mixture $(2.0 \mathrm{~mL})$ was incubated with $0.1 \mathrm{mg} / \mathrm{mL}$ pancreatic lipase from the porcine pancreas (332 U/mg protein, Nacalai Tesque, Inc., Kyoto, Japan) for $30 \mathrm{~min}$ at $37^{\circ} \mathrm{C}$. The enzymatic reaction was terminated via incubation in boiling water for 2 min. The amount of oleic acid released in the suspension was determined using a commercially available kit (NEFA C-Test, Wako). Experiments were repeated more than three times. Lipase inhibition was calculated as follows:

Lipase inhibition $(\%)=100-(B / A \times 100)$,

where $A$ is the amount of oleic acid released from the suspension without the addition of $\mathrm{AE}$ and $B$ is the amount of oleic acid released from the suspension in which AE or AE lacking polyphenol or SDF was added.

Removal of polyphenol from AE to assess the lipase inhibitory effect of polyphenol. Eighty milliliters of methanol was added to $1 \mathrm{~g}$ of $\mathrm{AE}$, and the mixture was sonicated for $30 \mathrm{~min}$. After centrifugation, pellets were freezedried and used for lipase measurements (25).

Measurement of cholesterol adsorption capacity in vitro. To explain the hypocholesterolemic effect of AE, a cholesterol micellar solution was prepared, and cholesterol adsorption experiments were conducted with AE, SDF and IDF. A mixed micellar solution containing $6.6 \mathrm{~mm}$ taurocholate, $0.6 \mathrm{~mm}$ phosphatidylcholine, $132 \mathrm{~mm}$ $\mathrm{NaCl}, 0.5 \mathrm{~mm}$ cholesterol, and $15 \mathrm{~mm}$ sodium phosphate, $\mathrm{pH} 7.4$ was prepared by sonication and stored at $37^{\circ} \mathrm{C}$ for at least $24 \mathrm{~h}(26)$. As AE contained $10 \%$ SDF and $5 \% \mathrm{IDF}, 5 \mathrm{~mL}$ of the micellar solution was mixed with $0,1,000$, or 2,000 mg of AE; 0, 100, or $200 \mathrm{mg}$ of SDF; or 0, 50 , or $100 \mathrm{mg}$ of IDF and shaken at $37^{\circ} \mathrm{C}$ for $2 \mathrm{~h}$. After centrifugation at $8,400 \mathrm{rpm}$ for $10 \mathrm{~min}$, the supernatant was filtered using a glass microfiber filter with a pore size $<1.6 \mu \mathrm{m}$ (GF/A 100 GE Healthcare Life, Tokyo, Japan). The cholesterol level in the filtrate was determined using a commercial kit as the non-adsorbed fraction. Cholesterol adsorption was calculated as follows:

Cholesterol adsorption $(\%)=100-(B / A \times 100)$, where $A$ is the cholesterol level in the filtrate lacking $\mathrm{AE}$, SDF and IDF and $B$ is the cholesterol level in the filtrate containing AE, SDF or IDF.

Analysis of the composition of the cecum microbiota by fluorescent in situ hybridization (FISH). Our probe was Bif153 and Erec482 (27, 28). In addition, the total number of microorganisms was determined by DAPI staining (Dojindo Laboratory, Kumamoto, Japan). To $0.5 \mathrm{~g}$ cecum content, $4.5 \mathrm{~mL}$ PBS and glass beads of a diameter of $4 \mathrm{~mm}$, were added. The samples were vortexed. Afterwards, supernatant was filtrated with fiber pepar (No. 1, Advantec, Saijyo, Japan). One milliliter of filtrate was mixed with $3 \mathrm{~mL}$ of $4 \%$ paraformaldehyde-PBS. This mixture was kept at $4^{\circ} \mathrm{C}$ overnight, and after that, preserved at $-80^{\circ} \mathrm{C}$ in a small quantity. Ten microliters of preserved solution was spread onto MAS coat slide glass (Matsunami Grass Ind., Ltd., Osaka, Japan). After drying for $1 \mathrm{~h}$ at room temperature and $15 \mathrm{~min}$ at $40^{\circ} \mathrm{C}$, the slide glass was dipped into $96 \%$ ethanol for $10 \mathrm{~min}$. The hybridization solution contained $3.75 \mathrm{M} \mathrm{NaCl} 20 \mu \mathrm{L}, 1 \mathrm{M}$ Tris-HCl (pH 8.0) $10 \mu \mathrm{L}$, 50 mM EDTA (pH 8.0) $10 \mu \mathrm{L}, 0.1 \%$ (wt/vol) BSA $10 \mu \mathrm{L}$, $2 \%$ (wt/vol) PolyA $10 \mu \mathrm{L}, 25 \%$ (wt/vol) dextran sulfate $40 \mu \mathrm{L}$, and fish probe $(100 \mathrm{ng} / \mathrm{dL}) 4 \mu \mathrm{L}$. Ten microliters of hybridization solution was added to the slide glass on which the cecum solution was already dried, and the cover glass was mounted carefully. Hybridization was conducted in a humid chamber at $40^{\circ} \mathrm{C}$, for 15-20 h. The slide glass was dipped in the washing solution ( $50 \mathrm{~mm} \mathrm{NaCl}, 4 \mathrm{~mm}$ Tris-HCl, $0.02 \mathrm{~mm}$ EDTA). After waiting for the cover glass to move away naturally, the cover glass was removed and the slide glass was kept for $20 \mathrm{~min}$. The slide glass was dipped in distilled water and dried at $40^{\circ} \mathrm{C}$. Four microliters of dapi solution was dropped on to the slide glass and the cover glass was mounted. After sealing the edges of the cover glass with nail polish, microscopic observation was performed using an Olympus BX53 fluorescence microscope combined with a u-REL-T apparatus. Measurements of the numbers of fluorescent cells were performed using the Win Roof program as a visual system (Mitani Corporation, Osaka, Japan).

Statistics. Data are expressed as the mean \pm standard deviation and analyzed by one-way ANOVA using SPSS 
Table 1. The composition of lyophilized pea pods and AE. (mg/g dry matter)

\begin{tabular}{lcc}
\hline \multicolumn{1}{c}{ Components } & Lyophilized pea pods & $\mathrm{AE}$ \\
\hline Reducing sugar & $335.0 \pm 52.3$ & $528.8 \pm 89.3$ \\
Protein & $51.6 \pm 5.9$ & $32.5 \pm 12.0$ \\
Total lipids & $33.3 \pm 23.1$ & $12.0 \pm 2.1$ \\
Sitosterol & $0.4 \pm 0.1$ & $1.1 \pm 0.3$ \\
Polyphenol & $114.4 \pm 0.4$ & $17.6 \pm 14.0^{*}$ \\
Vitamin C & $1.8 \pm 0.1$ & $0.2 \pm 0.2^{*}$ \\
Soluble fiber & $8.1 \pm 0.7$ & $91.7 \pm 0.8^{*}$ \\
Insoluble fiber & $292.0 \pm 7.3$ & $48.7 \pm 1.8^{*}$ \\
\hline
\end{tabular}

Values are means $\pm \operatorname{SD}(n=3)$.

$T$-test was conducted. Asterisk indicates significance compared with lyophilized pea pod $(p<0.05)$.

AE: autoclaved extract of pea pods.

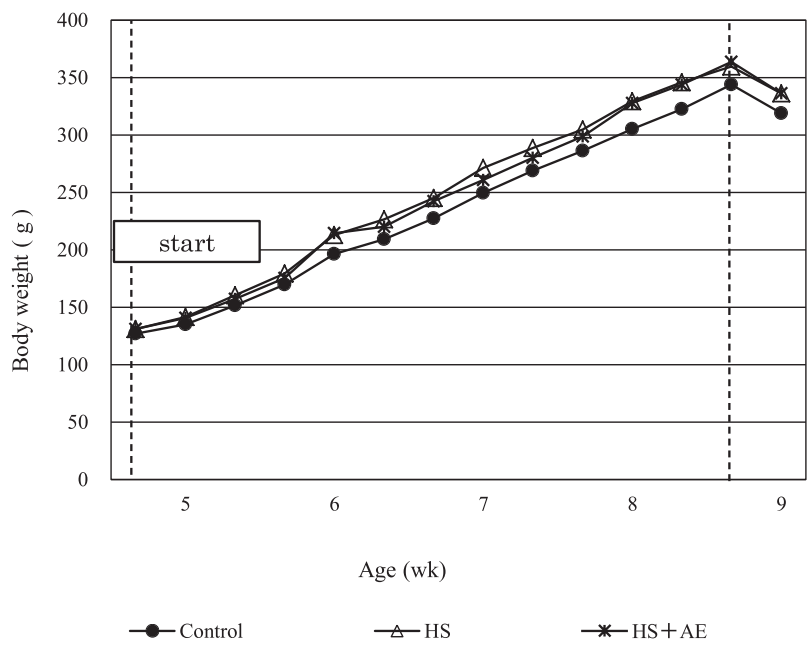

Fig. 1. Effect of AE on body weight gain. Body weight of each group was determined three times a week. Each value is mean \pm SD (Control group: $n=5$, HS group: $n=5$, HS + AE group: $n=5$ ). Start: the first day of consuming the experimental diet.

ver. 19.0 (SPSS Inc, Tokyo, Japan). Tukey's post-hoc test was used to determine significant differences among the groups. Values were considered significantly different at $p<0.05$. Grubb's test for outliers was only applied to the feces profile.

\section{RESULTS}

Component analysis of $A E$

The recovery of $\mathrm{AE}$ relative to the amount of pea pods was $32.5 \pm 0.70 \%$. The composition of $\mathrm{AE}$ was compared with that of the lyophilized pea pod (Table 1). Polyphenol content was dramatically reduced, but SDF, reducing sugar and sitosterol contents were increased. The pea pods contained ash $(6.6 \pm 0.5 \mathrm{~g} / 100 \mathrm{~g})(13)$, and the peas contained phenolic acids such as coumaric acid at $2.1 \pm 0.2 \mathrm{mg} / 100 \mathrm{~g}$, syringic acid at $41.7 \pm 0.0 \mathrm{mg} / 100 \mathrm{~g}$, and vanillic acid at $43.1 \pm 1.2 \mathrm{mg} / 100 \mathrm{~g}$, as well as some pigments such as carotenoids $(3.2 \pm 0.3 \mathrm{mg} / 100 \mathrm{~g})$ and chlorophyll

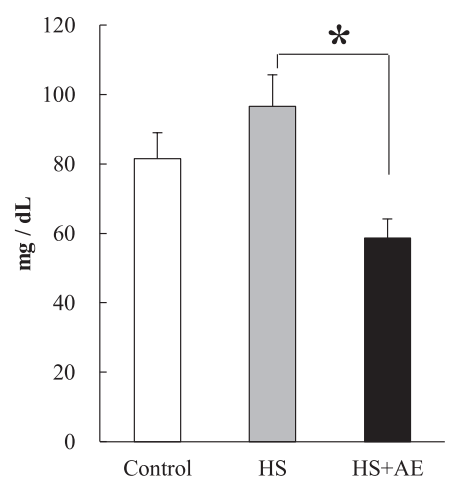

B

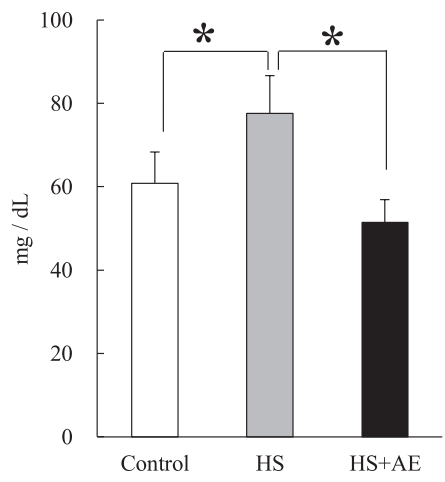

Fig. 2. Effect of the autoclaved extract (AE) of pea pods on serum lipid levels. Triglyceride (A) and cholesterol (B) concentrations are presented as the mean $\pm \mathrm{SD}$ $(n=5)$. Tukey's test was conducted. Asterisk denotes significance at $p<0.05$.

$(0.5 \pm 0.2 \mathrm{mg} / 100 \mathrm{~g})(25,29)$. We considered that the residual components of the pea pod and AE also contained components similar to those mentioned.

Effect of AE on body weight, food intake, and weight of liver and cecum

All animal experiments were conducted in the absence of diarrhea. Body weight gain was shown in Fig. 1. It was growing steadily and no significant difference was observed among the control, HS and AE groups. Food intake and food efficiency throughout the feeding period were the same for each rat in this experiment. In addition, there were no significant differences in the weights of the liver or cecum among the groups.

Serum and liver

The serum glucose level was not different among the groups (Data not shown). Serum triglyceride level in the AE group was significantly lower than those in the HS group (Fig. 2A). The serum cholesterol level of the AE group was significantly decreased compared with those in the HS group (Fig. 2B). However, total lipid, triglyceride and cholesterol levels in the liver were slightly lower in the AE group compared with the HS group. But it was not significant (Data not shown).

Effect of AE on the feces profile

Fecal wet weight did not indicate significant results among the groups. The same results were observed for total bile acids. The amount of total lipids of the AE 
Table 2. Effect of AE on the feces profile.

\begin{tabular}{lccc}
\hline \multirow{2}{*}{ Feces profile } & \multicolumn{3}{c}{ Groups } \\
\cline { 2 - 4 } & Control & HS & HS + AE \\
\hline Fecal wet weight, g/3 d & $6.87 \pm 1.34$ & $6.85 \pm 1.86$ & $6.64 \pm 0.90$ \\
Total bile acid, $\mu \mathrm{g} / 3 \mathrm{~d}$ & $236 \pm 96.2$ & $168 \pm 57.2$ & $178 \pm 45.9$ \\
Total lipid, mg/3 d & $356 \pm 93.0^{\mathrm{ab}}$ & $319 \pm 80.5^{\mathrm{a}}$ & $488 \pm 117^{\mathrm{b}}$ \\
Total lipid,\% of wet weight & $5.21 \pm 1.08^{\mathrm{ab}}$ & $4.73 \pm 0.81^{\mathrm{a}}$ & $7.55 \pm 2.24^{\mathrm{b}}$ \\
Triglyceride, \% of wet weight & $0.45 \pm 0.13^{\mathrm{a}}$ & $0.58 \pm 0.15^{\mathrm{ab}}$ & $0.69 \pm 0.08^{\mathrm{b}}$ \\
Cholesterol,\% of wet weight & $0.33 \pm 0.07$ & $0.43 \pm 0.14$ & $0.62 \pm 0.23^{*}$ \\
\hline
\end{tabular}

Results are expressed as means \pm SD $(n=5)$. Tukey's test was conducted.

Different superscript means significance $(p<0.05$.$) . * p$ value versus control was $p=0.059$.

HS: high sucrose, AE: autoclaved extract of pea pods.

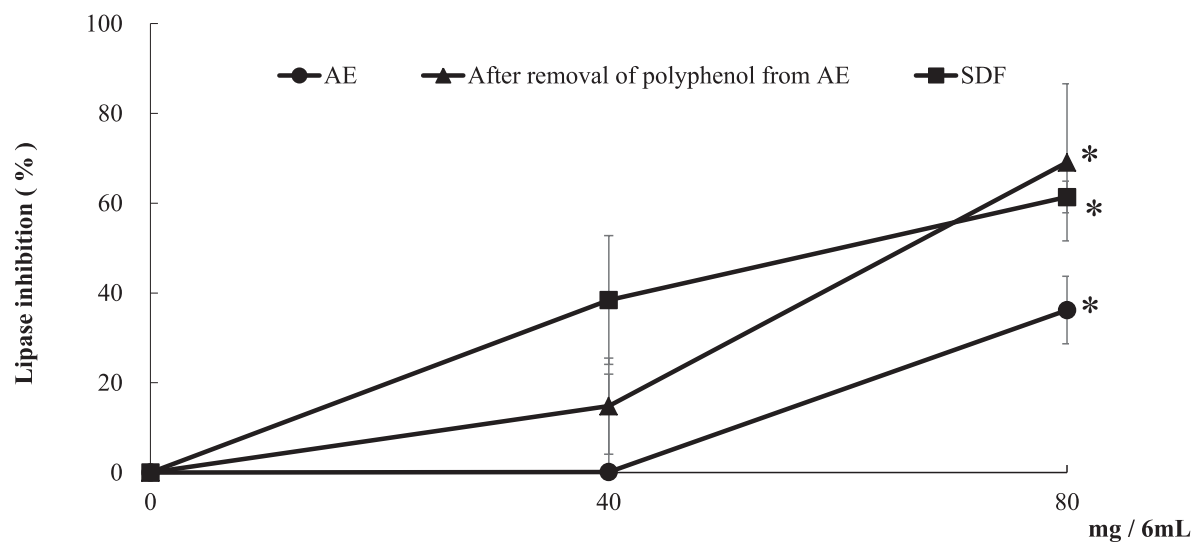

Fig. 3. Effect of $\mathrm{AE}$ on lipase activity in vitro. Inhibition of lipase activity was determined as the reduction of activity induced by AE. Experiments were repeated more than three times. Asterisks denote significant differences versus $0 \mathrm{mg} / 6 \mathrm{~mL}(p<0.05)$. AE: autoclaved extract of pea pods, SDF: soluble dietary fiber.

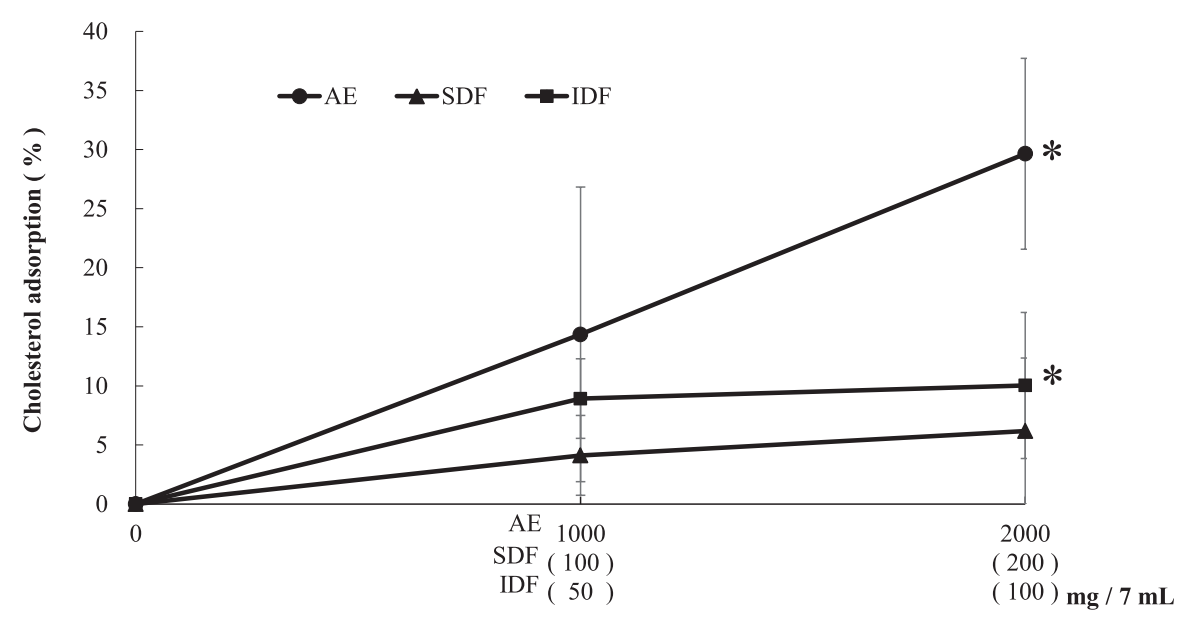

Fig. 4. Effect of AE on cholesterol adsorption in vitro. A cholesterol micellar solution was prepared, and cholesterol adsorption experiments with AE, SDF, or IDF were conducted. Asterisks denote significant differences versus $0 \mathrm{mg} / 7 \mathrm{~mL}$ $(p<0.05)$.

group was significantly increased compared with that in the HS group. However the amount of triglyceride and cholesterol of the AE group tended to increase compared with that of the HS group and control group. No significant difference was observed because there were individual differences in the amount of feces. There- fore, total lipids, triglyceride and cholesterol content (\% of wet weight) in the feces were estimated. Total lipids and triglyceride contents in the AE group significantly increased compared with the HS group and control group, respectively. However cholesterol content in the AE group tended to increase compared with control 
Table 3. Effect of AE on Bifidobacteria and Clostridia in the cecum.

\begin{tabular}{cccc}
\hline \multirow{2}{*}{$\begin{array}{c}\text { Cy3/DAPI } \\
\text { (Bifidobacteria or Clostridia/Total microbiota) }\end{array}$} & \multicolumn{2}{c}{ Groups } & HS + AE \\
\cline { 2 - 4 } & Control & HS & $0.239 \pm 0.053^{\mathrm{b}}$ \\
Bifidobacteria & $0.186 \pm 0.046^{\mathrm{a}}$ & $\begin{array}{l}0.178 \pm 0.050^{\mathrm{a}} \\
0.215 \pm 0.043\end{array}$ \\
\hline Clostridia & $0.234 \pm 0.056$ & $0.223 \pm 0.050$ & 0.250 \\
\hline
\end{tabular}

Results are expressed as means \pm SD ( $n=3$ /group). Tukey's test was conducted.

Different superscript means significance $(p<0.05$.).

HS: high sucrose, AE: autoclaved extract of pea pods.

group $(p=0.059)$ (Table 2).

Effect of AE on pancreatic lipase activity

$\mathrm{AE}$ inhibited pancreatic lipase activity in the assay system using triolein. AE at $13.3 \mathrm{mg} / \mathrm{mL}$ significantly inhibited the enzymatic activity by more than $40 \%$ compared to $0 \mathrm{mg} / \mathrm{mL}$. After polyphenol removal, the lipase inhibitory activity of AE at 6.6 and $13.3 \mathrm{mg} / \mathrm{mL}$ was increased. SDF exhibited greater inhibitory activity than $\mathrm{AE}$ at 6.6 and $13.3 \mathrm{mg} / \mathrm{mL}$, but the differences to AE were not significant (Fig. 3).

Effect of AE on cholesterol adsorption

$\mathrm{AE}$ was demonstrated to adsorb cholesterol. Compared with the control, 2,000 $\mathrm{mg}$ of AE adsorbed approximately $33 \%$ of cholesterol, and this difference to $0 \mathrm{mg}$ was significant. In addition, $100 \mathrm{mg}$ of IDF displayed significant cholesterol adsorption activity compared with that in the control (Fig. 4).

Effect of the AE on intestinal microbiota

The amount of bifidobacteria in the cecum of the AE group was significantly increased compared with that in the HS group. Clostridia in the AE group was decreased compared with that in the HS group but was not significant (Table 3).

\section{DISCUSSION}

The main finding in our study was that compared with the HS group, the serum lipid levels, including triglycerides and cholesterol in the AE group, were significantly lower.

Dietary fiber increased bile acid and lipid contents in feces, and as a consequence, blood lipid levels were decreased $(4,5)$. In our study, the amount of bile acids in the feces of the AE group did not increase compared with those in the HS group. Conversely, the amount of total lipids in the feces from the AE group was significantly increased compared with those in the HS group. Additionally, lipid content in the feces of the AE group indicated significant increase compared with the HS group. Consequently, we hypothesized that serum triglyceride and cholesterol levels were lowered because of the increase in the fecal total lipid excretion. It is conceivable that rats had individual differences in the amount of feces, lipid excretion and water content of feces because it was impossible to collect all samples at the time of defecation. Therefore, it was difficult to obtain significant results for the feces profile. This time, we recalculated total lipids, triglyceride and cholesterol content (\% of fecal wet weight) and the AE group tended to increase compared with the HS group.

Pancreatic lipase hydrolyses triglycerides. Thus, the excretion of triglyceride in the feces will increase upon lipase inhibition. AE at $13.3 \mathrm{mg} / \mathrm{mL}$ inhibited lipase activity by more than $40 \%$. We hypothesized that the inhibitory effect of AE on pancreatic lipase was attributable to polyphenol or SDF present in the AE. As previously reported, SDF and polyphenol have lipase-inhibiting activity $(24,30)$. Slanc et al. reported that methanol extracts from Pisum sativum inhibited pancreatic lipase activity in vitro, and the removal of polyphenol from the extract decreased its inhibitory activity to less than $40 \%$ of the control (31). All plant materials, in addition to peas, contain phenolics (13). In our study, the lipaseinhibiting activity of $13.3 \mathrm{mg} / \mathrm{mL}$ AE was increased after the removal of polyphenol. We assumed that polyphenol in the AE did not inhibit lipase activity or it was structurally changed by autoclaving.

SDF prepared from AE exhibited enhanced the lipaseinhibitory activity. Dietary fibers, specifically SDF and polyphenol, have been reported to precipitate cholesterol and bile salt $(26,32-34)$. In this study, AE adsorbed cholesterol micelles in vitro. More than 30\% cholesterol was adsorbed by $2,000 \mathrm{mg}$ of $\mathrm{AE}$. We assumed that cholesterol adsorption was caused by IDF. Because of the significant difference by IDF compared with the findings in the absence of $\mathrm{AE}$, it may be indicated that IDF in $\mathrm{AE}$ promotes cholesterol excretion. In addition, IDF has not been reported to adsorb cholesterol. We demonstrated that IDF has a greater adsorption capacity than SDF. By autoclaving, the contents such as barley or wheat, amino acids and glycosyl components have been changed $(35,36)$. Similarly, the structure of IDF might have been changed by autoclaving. In the case of hulled barley, the relative viscosity of an autoclaved sample was increased compared with an untreated sample (36). We hypothesized the relative viscosity of IDF has also been increased by autoclaving. In our study, $\mathrm{SD}$ rats were fed $30 \mathrm{~g}$ per day of the experimental diet on average, amounting to AE $0.9 \mathrm{~g}$ per day, SDF $90 \mathrm{mg}$, and IDF $45 \mathrm{mg}$. To express cholesterol adsorption, $0.9 \mathrm{~g}$ may be insufficient. But there is a possibility of cholesterol adsorption by continuous feeding of AE.

Moreover, there were no significant differences in 
weight gain or food intake among the groups in this study. These results illustrated that $\mathrm{AE}$ did not affect growth or food intake. In our feed, AE replaced cornstarch, not cellulose. We have two reasons: one, a reducing sugar makes up more than half the content of $\mathrm{AE}$, while dietary fiber comprises $10 \%$ of AE. The other reason is that cellulose has no effect on serum lipids (6, 37).

$\mathrm{AE}$ is a mixture including various ingredients. From the results, AE includes plant sterols, such as sitosterol (38). It has been well established that plant sterols and stanols have hypocholesterolemic activity by inhibiting cholesterol absorption in the intestine. $\beta$-Sitosterol $(0.4 \mathrm{~mm})$ was able to reduce the solubility of cholesterol to $43 \%$ in a model intestinal solution system (39). One gram of AE contains $1 \mathrm{mg}$ of sitosterol. It corresponds to $2.5 \mathrm{~mm}$. Consequently, dietary cholesterol was excreted in the feces by plant sterol (40). Nevertheless, cholesterol excretion in feces of the AE group did not significantly increase.

$\mathrm{AE}$ also increase bifidobacteria in the cecum. It is well known that bifidobacteria is beneficial for humans, and 96 cases in the literature on the cholesterol-lowering effect of bifidobacteria or other prebiotics (key words: bifidobacteria, cholesterol) were obtained in PubMed (41). When we determined neutral sugar from AE, xylose was observed $(2.5 \pm 0.6 \mathrm{mg} / \mathrm{g}$ of dry matter). Xylo-oligosaccharide reported to have prebiotic activity (42). Many of the bifidobacteria having a cholesterollowering activity showed the ability to assimilate cholesterol (43). This report helps demonstrate that cholesterol excretion in the feces of the AE group did not increase significantly because of cholesterol assimilation by bifidobacteria. This hypothesis concerning the cholesterol-lowering effect of AE has the most potential in this study.

From these results, it's difficult to specify the hypolipidemic factor because $\mathrm{AE}$ is a mixture. In addition, we did not obtain significant results for liver lipid or fecal bile acids. Therefore, we cannot exclude the possibility of HMG-CoA reductase inhibition and CYP7A activation by AE.

Compared with lyophilized pea pods, the amount of polyphenol was dramatically decreased and the amount of soluble fiber was increased by more than 10-fold in AE. As in the animal experiment using lyophilized pea pods under the same conditions as in this study, we did not observe any significant data on the lipid-lowering effect. The functionality of the pea pod may be activated by autoclaving.

Our study revealed that pea pods developed into a novel functional food for controlling serum triglyceride and cholesterol by using the method of autoclaved extraction because pea pods could not indicate activity. The AE of pea pods with health-promoting effects in humans may resolve one of the problems of food wastage.

\section{REFERENCES}

1) Duenas M, Estrella I, Hernandez T. 2004. Occurrence of phenolic compounds in the seed coat and the cotyledon of peas (Pisum sativm L.). Eur Food Res Technol 219: 116-123.

2) Mateos-Aparicio I, Redondo-Cuenca A, VillanuevaSuarez M-J. 2012. Broad bean and pea by products as sources of fiber-rich ingredients: potential antioxidant activity measured in vitro. J Sci Food Agric 92: 697-703.

3) Kim M, Shin HK. 1998. The water-soluble extract of chicory influences serum and liver lipid concentrations, cecal short-chain fatty acid concentrations and fecal lipid excretion in rats. J Nutr 128: 1731-1736.

4) Cho LJ, Lee C, Ha TY. 2007. Hypolipidemic effect of soluble fiber isolated from seeds of Cassia tora Linn. In rats fed a high-cholesterol diet. J Agric Food Chem 55: 1592-1596.

5) Moundras C, Behr SR, Remesy C, Demigne C. 1997. Fecal losses of sterols and bile acids induced by feeding rats guar gum are due to greater pool size and liver bile acid secretion. J Nutr 127: 1068-1076.

6) Nishina PM, Freedland RA. 1990. The effects of dietary feeding on cholesterol metabolism in rats. J Nutr 120: 800-805.

7) Chen H-L, Haack VS, Janecky CW, Vollendorf NW, Marlett JA. 1998. Mechanisms by which wheat bran and oat bran increase stool weight in humans. Am J Clin Nutr 68: $711-719$.

8) Ruiz-Roso B, Quintela JC, de la Fuente E, Haya J, PerezOlleros L. 2010. Insoluble carob fiber rich in polyphenols lowers total and LDL cholesterol in hypercholesterolemic subjects. Plant Foods Hum Nutr 65: 50-56.

9) Iwata E, Hotta H, Goto M. 2009. The screening method of a bifidogenic dietary fiber extracted from inedible parts of vegetables. J Nutr Sci Vitaminol 55: 385-388.

10) Makelainen H, Forssten S, Saarinen M, Stowell J, Rautonen N, Ouwehand AC. 2010. Xylo-oligosaccharide enhance the growth of bifidobacteria and Bifidobacterium lactis in a simulated colon model. Benef Microbes 1: 81-91.

11) Adam A, Levrat-Verny M-A, Lopez HW, Leuillet M, Demigne C, Remesy C. 2001. Whole wheat and triticale flours with differing viscosities stimulate cecal fermentations and lower plasma and hepatic lipids in rats. J Nutr 131: 1770-1776.

12) Shimizu-I A, Udagawa H, Kobayashi-HK, Mura K, Tokue C, Takita T, Arai S. 2009. Hypocholesterolemic effect of peanut skin and its fractions: A case record of rats fed on a high-cholesterol diet. Biosci Biotechnol Biochem 73: 205-208.

13) Klepacka J, Gujska E, Michalak J. 2011. Phenolic compounds as cultivar- and variety-distinguishing factors in some plant products. Plant Foods Hum Nutr 66: 64-69.

14) Gusakov AV, Kondratyeva EG, Sinitsyn AP. 2011. Comparison of two methods for assaying reducing sugars in the determination of carbohydrase activities. Int J Anal Chem 10: 1155-1158.

15) Lowry OH, Rosebrough NJ, Farr AL, Randall RJ. 1951. Protein measurement with the folin phenol reagent. $J$ Biol Chem 193: 265-275.

16) Folch J, Lees M, Sloane Stanley GH. 1957. A simple method for the isolation and purification of total lipids from animal tissues. J Biol Chem 226: 497-509.

17) Roe JH, Mills MB, Oesterling MJ, Damron CM. 1948. 
The determination of kiketo-1-gulonic acid, dehydro1 -ascorbic acid, and 1-ascorbic acid in the same tissue extract by the 2,4-dinitrophenylhydrazine method. J Biol Chem 174: 201-208.

18) Brat P, George S, Bellamy A, Chaffaut LD, Scalbert A, Mennen L, Arnault N, Amiot MJ. 2006. Daily polyphenol intake in france from fruit and vegetables. J Nutr 136: 2368-2373.

19) Prosky L, Asp NG, Furda I, DeVries JW, Schweizer TF, Furda I. 1988. Determination of insoluble, soluble, and total dietary fiber in foods and food products, interlaboratory study. J Assoc Off Anal Chem 71: 1017.

20) Reeves PG, Nielsen FH, Fahey GC Jr. 1993. AIN-93 purified diets for laboratory rodents: Final reports of American Institute of Nutrition Ad Hoc Writing Committee on the reformation of the AIN-76A rodent diet. J Nutr 123: 1939-1951.

21) Yang M-H, Wang C-H, Chen H-L. 2001. Green, oolong and black tea extracts modulate lipid metabolism in hyperlipidemia rats fed high-sucrose diet. J Nutr Biochem 12: 14-20.

22) Arimoto K, Adachi K, Yamaga N. 1982. $7 \beta, 12 \beta$-Dihydroxy- $5 \beta$-cholan- 24 oic acid as an internal standard for quantitative determination of bile acids by gas chromatography. Steroids 39: 631-641.

23) Yamaga N, Adachi K, Kohara H, Shimizu K. 1987. Internal standards for quantitative gas chromatography of individual bile acids after group separation of bile acids in urine. J Chromatogr 422: 25-32.

24) Iwata E, Hotta H, Goto M. 2012. Hypolipidemic and bifidogenic potentials in the dietary fiber prepared from Mikan (Japanese mandarin orange: Citrus unshiu) albedo. J Nutr Sci Vitaminol 58: 175-180.

25) Bhattacharya S, Malleshi NG. 2012. Physical chemical and nutritional characteristics of premature-processed and matured green legumes. J Food Sci Technol 49: 459-466.

26) Ikeda I, Imasato Y, Sasaki E, Nakayama M, Nagao H, Takeo T, Yayabe F, Sugano M. 1992. Tea catechins decrease micellar solubility and intestinal absorption of cholesterol in rats. Biochim Biophy Acta 1127: 141-146.

27) Takata T, Matsumoto K, Nomoto K. 2004. Development of multi-colon FISH method for analysis of seven Bifidobacterium species in human feces. J Microbiol Methods 58: $413-421$.

28) Hayashi H, Sakamoto M, Kitahara M, Benno Y. 2006. Diversity of the Clostridium cocoides group in human fecal microbiota as determined by $16 \mathrm{~S}$ rRNA gene library. FEMS Microbiol Let 257: 202-207.

29) Mateos-Aparicio I, Redondo-Cuenca A, VillanuevaSuárez M-J, Zapata-Revilla M-A, Tenorio-Sanz M-D. 2010. Pea pod, broad bean pod and okara, potential sources of functional compounds. Food Sci Technol 43: 1467-1470.

30) Mineo S, Noguchi A, Nagakura Y, Kobori K, Ohta T, Saka- guchi E, Ichiyanagi T. 2015. Boysenberry polyphenol suppressed elevation of plasma triglyceride level in rats. J Nutr Sci Vitaminol 61: 306-312.

31) Slanc P, Doljak B, Kreft S, Lunder M, Janes D, Strukelj B. 2009. Screening of selected food and medical plant extracts for pancreatic lipase inhibition. Phytother Res 23: $874-877$.

32) Vinarova L, Vinarov Z, Damyanova B, Tcholakova S, Denkov N, Stoyanov S. 2015. Mechanisms of cholesterol and saturated fatty acid lowering by Quillaja saponaria extract, studied by in vitro digestion model. Food Funct 6: 1319-1330.

33) $\mathrm{Hu} \mathrm{G}, \mathrm{Yu} W .2013$. Binding of cholesterol and bile acid to hemicelluloses from rice bran. Int J Food Sci Nutr 64: 461-466.

34) Nsor-Atindana J, Zhong F, Joseph MK. 2012. In vitro hypoglycemic and cholesterol lowering effects of dietary fiber prepared from cocoa (Theobroma cacao L.) shells. Food Funct 3: 1044-1050.

35) Branton SL, Lott BD, May JD, May JD, Hedin PA, Austin FW, Latour MA, Days EJ. 1996. The effect of nonautoclaved and autoclaved water-soluble wheat extracts on the growth of clostridium perfringens. Poultry Sci 75: 335-338.

36) Campbell GL, Classen HL, Balance GM. 1986. Gamma irradiation treatment of cereal grains for chick diet. J Nutr 116: 560-569.

37) Behall KM, Lee KH, Moser PB. 1986. Blood lipids and lipoproteins in adults men fed four refined fibers. Am J Clin Nutr 39: 209-214.

38) Schrick K, Cordova C, Li G, Murray L, Fujioka S. 2011. A dynamic role for sterols in embryogenesis of Pisum sativum. Phytochemistry 72: 465-475.

39) Matsuoka K, Kase A, Matsuo T, Ashida Y. 2015. Competitive solubilization of cholesterol/cholesteryl oleate and seven species of sterol/stanol in model intestinal solution system. J Oleo Sci 64: 783-791.

40) De Smet, E, Mensink RP, Plat J. 2012. Effect of plant sterols and stanols on intestinal cholesterol metabolism: Suggested mechanisms from past and present. Mol Nutr Food Res 56: 1058-1072.

41) Lee D, K, Jang S, Baek EH, Kim MJ, Lee KS, Shin HS, Chung MJ, Kim JE, Lee KO, Ha NJ. 2009. Lactic acid bacteria affect serum cholesterol levels, harmful fecal enzyme activity, and fecal water content. Lipid Health Dis 8: 21 .

42) Manisseri C, Gudipati M. 2012. Prebiotic activity of purified xylobiose obtained from ragi (Eleusine coracana, Indaf-15) bran. Indian J Microbiol 52: 251-257.

43) Bordoni A, Amaretti A, Leonardi A, Boschetti E, Danesi F, Matteuzzi D, Roncaglia L, Raimondi S, Rossei M. 2013. Cholesterol-lowering probiotics: in vitro selection and in vivo testing of bifidobacteria. Appl Microbiol Biotechnol 97: 8273-8281. 